\title{
Barcode Based Billing System for Supermarket using Android Smartphone
}

\author{
Mansi Karanjekar ${ }^{1}$, Pratiksha Rode ${ }^{2}$, Sidhant Mankar ${ }^{3}$, Priyanka Meshram ${ }^{4}$ \\ Student, Department of Information Technology, Rajiv Gandhi College of Engineering and Research, \\ Nagpur, India ${ }^{1,2,3,4}$
}

\begin{abstract}
The Smart Shopping methodology is collaborating ease in smart shopping and the sense of security money wise as well as for customer satisfaction while doing shopping offline. This is implemented using an Android application. In Shopping mode, the customer needs to physically pick up his purchase, carry cash, along with them and wait in the long queue to make payments. The application mentioned here would read the Bar code of the product \& add it to the shopping cart in the application. It provides methods to change the quantity of product purchased and edit the list. Along with that customer can easily view his cart, bill and amount and products.
\end{abstract}

Keywords: Barcode, barcode scanner, android, Android smartphone.

\section{INTRODUCTION}

It is a real-time capturing system for consumer supplies using Quick Response Barcode in Android smartphone. In recent years, extensive research has been carried out on vision-based automatic identification technology that recognizes image codes using smartphones to provide various services that can recognize the authenticity of any product. Using Barcode with special symbols and split the data back to their Barcode pattern where these Barcode patterns can be read by Android smartphones. So Barcode verifies products by capturing it through the smartphone, then decodes and sends it to the server for authentication.

In today's life going to malls for shopping is increasing rapidly. People take the item and put it into the trolley. After done with shopping they go for billing at the Billing counter but as there are many people standing in Queue for billing purpose. So the Bar code image using smartphones to provide various services that can recognize the authenticity of any product. Bar code verifies products by capturing it through the smartphone, then decodes the item. The user will scan the item which he wants to purchase with the help of a scanner provided by this app. After scanning the item a web service will get called which will create a connection with the database of the shop. As the connection is established, the user is now synched with the database and information related to that item is provided to him. In this whole procedure, the overall time of scanning of individual items is saved and thus reducing the time of the shopping.

\section{LITERATURE SURVEY}

According to International journal of scientific research "A study of factors affecting online shopping behaviour of consumer" [6] The industry has been advocating "Smart Shopping" for many years by adopting various technologies to enhance the shopping experience at the shopping environment. The vision of smart shopping is to provide ease of shopping to customers and ease in gaining products and ease in billing. Dr Gagandeep Nagara and Dr R. Gopal[1] refer that the application described would be a prototype that would shape the future $\&$ there still remains much to do in terms of development and improvement of the existing models. Applications created with ease of understanding and the design can be created and tailored to the shopping process to make it more effective and user-friendly, thus making it easier \& convenient for the users to do the entire shopping process with the use of this application. The advantages of mobile commerce are- customer satisfaction, Cost savings, Improvement of Customer relations. While coming across various technologies such as Online Shopping, where items are purchased online through various websites, the drawbacks encountered were Fraud, Shipping cost. In the traditional shopping method, various difficulties faced are Long queues, Huge waiting time. Applications created with ease of understanding and the design can be created and tailored to the shopping process to make it more effective and user-friendly, thus making it easier \& convenient for the users to do the entire shopping process with the use of this application. 
Vol. 8, Issue 2, February 2019

\section{PROPOSED WORK}

In the proposed work, the user will scan the item which he wants to purchase with the help of a scanner provided by this app. After scanning the, item a web service will get called which will create a connection with the database of the shop. As the connection is established, the user is now synched with the database and information related to that item is provided to him. In this whole procedure, the overall time of scanning of individual items is saved and thus reducing the time of the shopping. The assumptions for the app are Shop has Wi-Fi facility and User has installed the app.

\section{Web Service}

A Web service is a software which can connect any device that is active on the internet to another and establish communication between them. It uses HTTP as a common communication protocol. Web service is required to establish communication between the Android device and Shop's database to exchange information.

\section{Database}

The shop's database is designed using MYSQL. It provides an interface with the help of which any database can be easily designed. The shop's database consists of the following things. It provides information about the availability of the items, their unique id, product id etc. It provides detailed information on each item from its manufacturing date, price, weight, etc. The customer's information will be stored in this table including his address and phone number for better convenience. It will have information about the time when a customer has logged in after scanning the shop's barcode till the successful payment completion. It will have detail information about the shop's name, its branch and unique id (barcode) that will be retrieved at the time of scanning of the shop's barcode. It maintains customer information about his purchases, total amount, cart number and all those information that is required to generate a final bill.

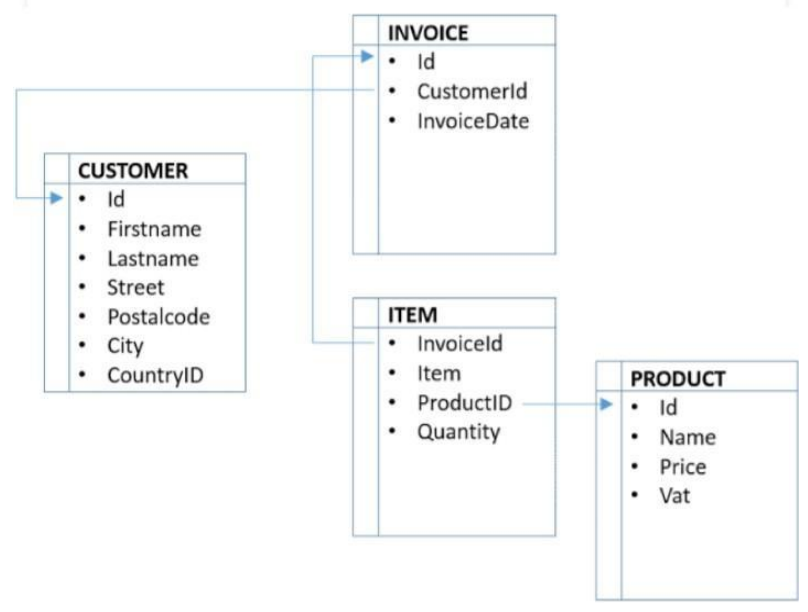

Fig 1: Database schema for supermarket

\section{METHODOLOGY}

In recent years smartphones are becoming the most important gadget for maintaining the daily activities and it is also used by a maximum of the population worldwide. Now a day's maximum operation is based on the automation but then for billing, we have to stand in the long queue where automation is not there in the billing system. Based on an automatic barcode scanning method we can reduce the waiting time for billing the products and reduce the manpower. Day by day we try to reduce the man work but for scanning and billing process still, us depending on the manpower. Now, this barcode based billing system application. we are proposing can help in reducing all these chaos related to a long queue at the billing counter and can also save a good amount of time.

In this application, the sensors will sense the product barcodes and send the product details to the computer system where the billing will be done. For the implementation of this application, it is required to create an android app for the Android user and fetch the data through the .net code. For all this purpose it requires to create the database and the database must be global because the database is used by the android app user and the system user. 
Vol. 8, Issue 2, February 2019

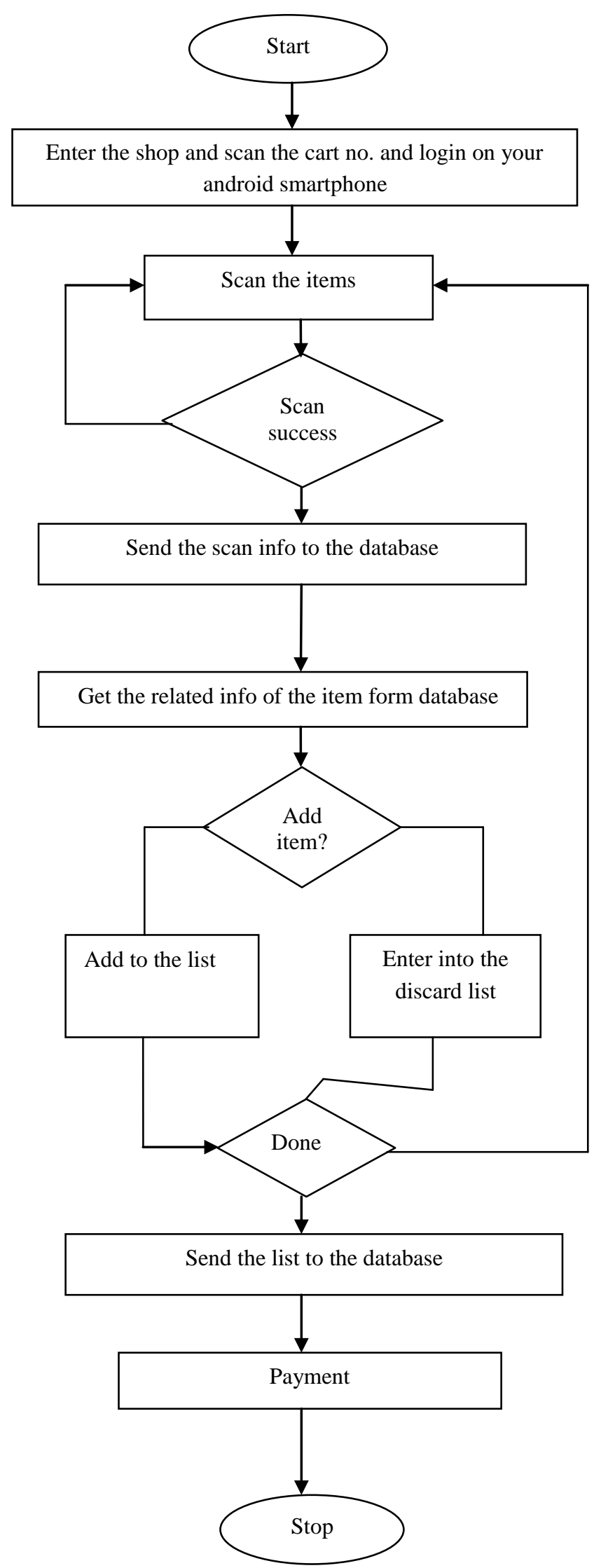

Fig 2: Flowchart 


\section{International Journal of Advanced Research in Computer and Communication Engineering}

Vol. 8, Issue 2, February 2019

\section{IMPLEMENTATION DETAILS}

Application Features of smart shopping app are Reduces scanning time, Personalization of items, Maintains History of purchased products.

Some technologies which are used in implementation are Android SDK, ADT (Android Development Tool), MySQL, web service.

ANDROID SDK- It is the software development kit used for developing android apps. This kit includes Debugger, Libraries, Quick emulator

Android virtual device is used to get a view of an app. This SDK will be included in the android in the bundle called a ADT bundle. This ADT bundle is then extracted to get the above facilities.

ANDROID DEVELOPMENT TOOL - It is the plugin for the eclipse with the help of which following tasks can be performed Set up new Android projects, Creating a new application UI.

MYSQL- Multiple administrative tools, Programs and libraries, Application programming interfaces

In total it provides an environment in which the android projects can be imported, build and run successfully.

\section{OUTPUT :}

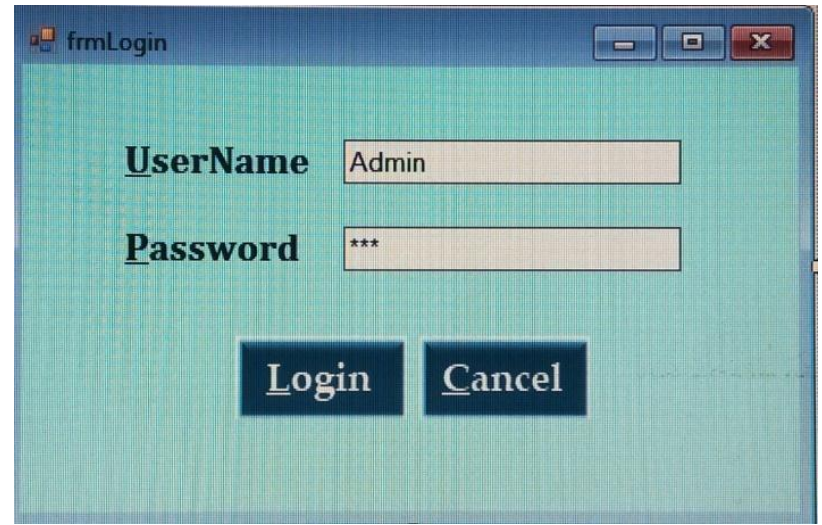

Fig 3: login page of the billing counter

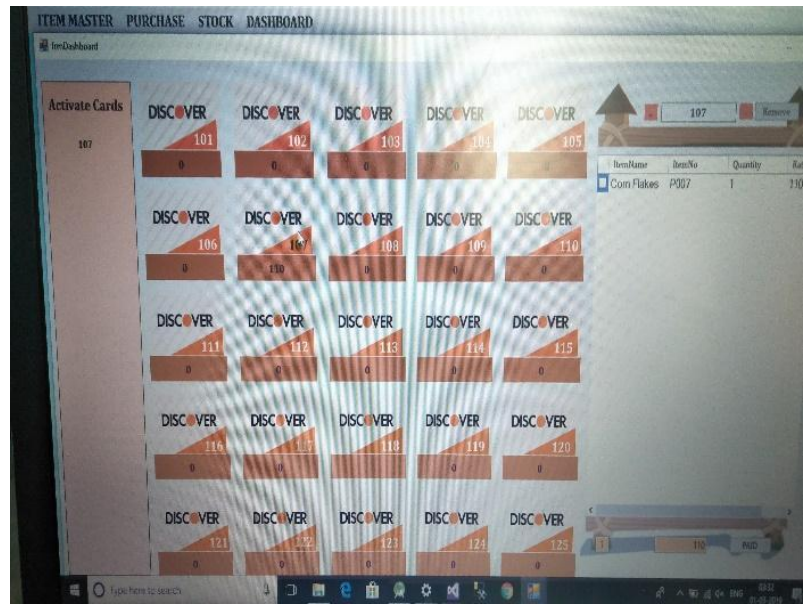

Fig 4: dashboard of billing counter 
Vol. 8, Issue 2, February 2019

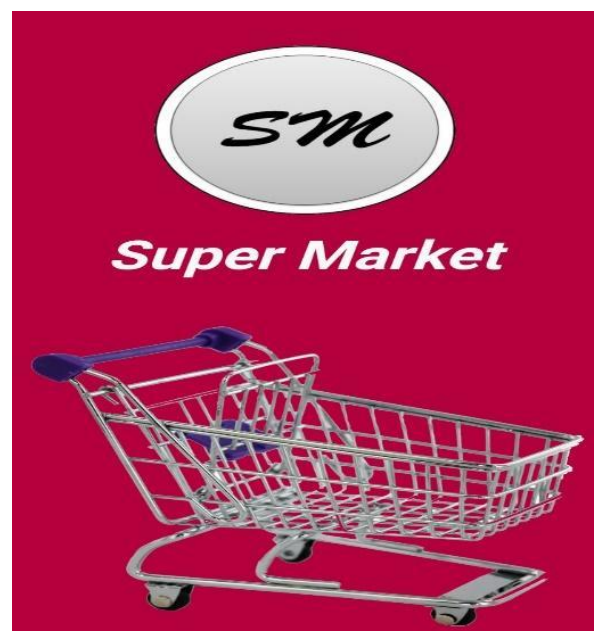

Fig 5: main page of the android app

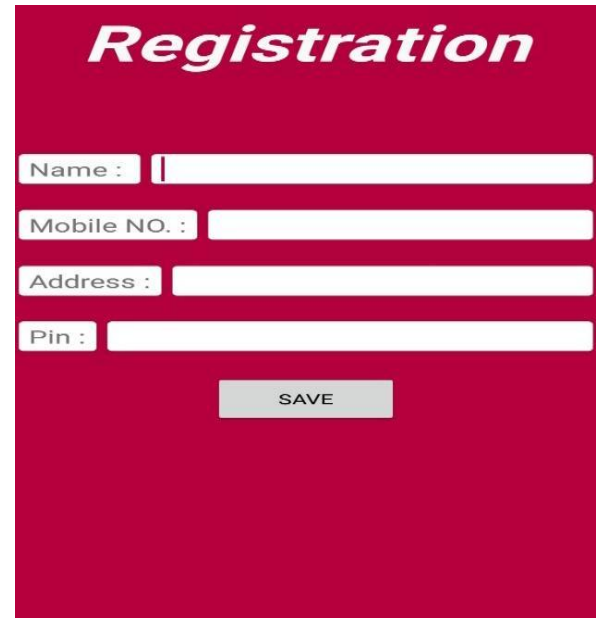

Fig 6: registration page

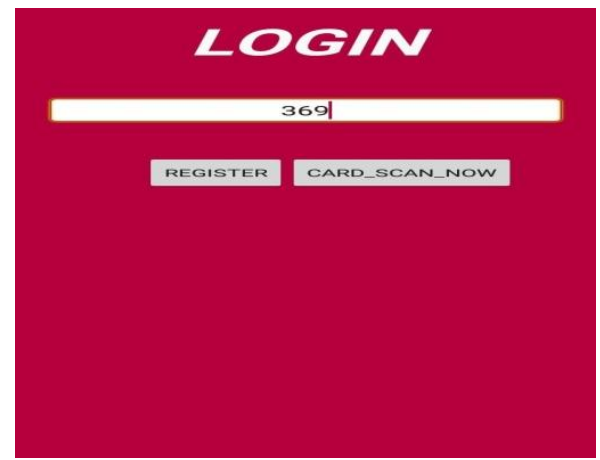

Fig 7: login page for customer 


\section{International Journal of Advanced Research in Computer and Communication Engineering}

Vol. 8, Issue 2, February 2019

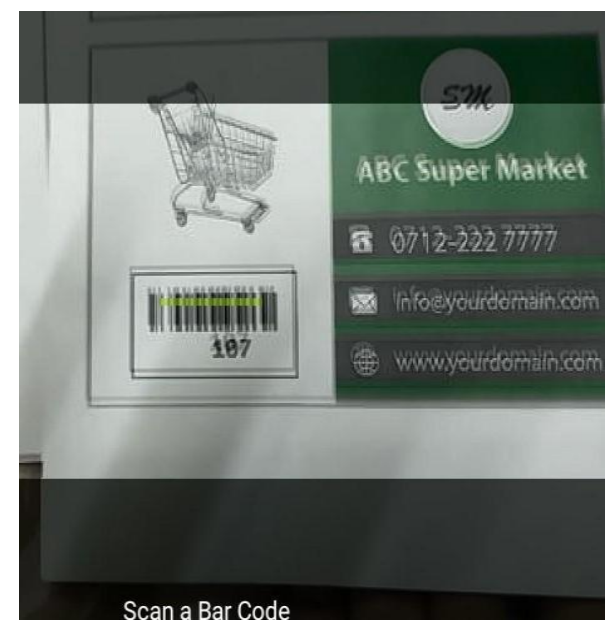

Fig 8: using android smartphone scan the barcode for cart entry

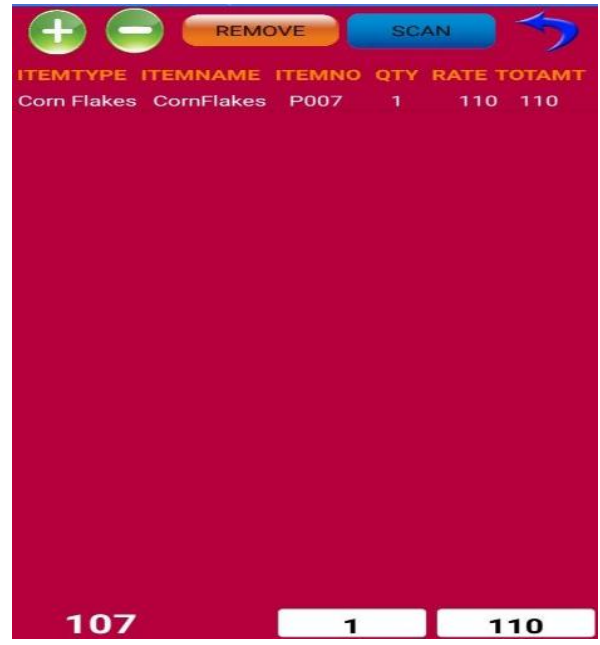

Fig 9: scan the product using android app and the final screen appears.

\section{CONCLUSION}

Nowadays demand for mobile shopping is increasing the requirement of the more secure, safe and reliable transaction is of utmost demand. Smartphones, that have become an important part of today's life, have reduced all the efforts that are required for shopping. With camera feature in it, the user can scan the Barcode of the item to be purchased and then directly add it into the cart. There are two advantages to it. first no need to stand in the queue for a long time in malls just for scanning the item, second there will be no scope for the frauds that happen in mobile shopping. The items so far purchased by the customer will be maintained in the app that can be used by the customer in the next purchase. The transactions that will take place frequently with the shop's database will be made secure. This will ensure no modifications in the shop's database either by the customer or by any unauthorized user.

\section{REFERENCES}

[1] Dr.Gagandeep Nagra, Dr.R.Gopal, "An study of Factors Affecting on Online Shopping Behavior of Consumer”, International Journal of scientific and research publications, Volume3, issue 6, June 2013, ISSN:2250-3153

[2] Constantinides, E., (2004), "Influencing the online consumer's behaviour: The web experiences", Internet Research, vol. 14, no. 2, pp.111-126.

[3] Ya-Lin Lee and Wen-Hsiang Tsai, Senior Member, IEEE,"A New Data Transfer Method via Signal-rich-art Code Images Captured by Mobile Devices", VOL. 25, NO. X, 2015.

[4] Max E. Vizcarra Me lgar, Luz A, Melgar Santander,"An Alternative Proposal of Tracking Products Using Digital Signatures and QR Codes", Aug. 2015.

[5] B. Davis, "Signal rich art: enabling the vision of ubiquitous computing," International Journal of Advanced Research in Computer Engineering \& Technology (IJARCET) Volume 4 Issue 3, March 2015 